\title{
POTENSI ASAP CAIR DARI KAYU BINTANGUR SEBAGAI BIOPESTISIDA PENGENDALI JAMUR Schizophyllum commune
}

\section{THE POTENTIAL OF WOOD VINEGAR FROM BINTANGUR WOOD AS BIOPESTICIDE FOR Schizophyllum commune FUNGAL CONTROL}

\author{
Juanita $^{1)}$, Hasan Ashari Oramahi ${ }^{2)}$, Farah Diba ${ }^{3)}$ \\ 2) Fakultas Kehutanan, Universitas Tanjungpura, Pontianak, \\ ${ }^{1), 3)}$ Program Studi Magister Ilmu Kehutanan, Fakultas Kehutanan, Universitas \\ Tanjungpura \\ email: oramahi@fahutan.untan.ac.id
}

diterima : 15 Maret 2020; dipublikasi : 30 Maret 2020

DOI : 10.32528/bioma.v5i1.3684

\begin{abstract}
ABSTRAK
Penelitian ini bertujuan untuk mengevaluasi sifat antijamur asap cair kayu bintangur dalam menghambat pertumbuhan jamur $S$. commune secara in vitro. Asap cair kayu bintangur yang digunakan sebanyak tiga jenis hasil dari pirolisis pada suhu 370, 400 dan $430^{\circ} \mathrm{C}$. Medium PDA digunakan untuk efikasi asap cair kayu bintagur terhadap pertumbuhan jamur $S$. commune. Efikasi asap cair kayu bintangur terhadap jamur $S$. commune dengan rancangan acak lengkap faktorial, terdiri atas suhu pembuatan asap cair kayu bintangur $\left(370,400\right.$, dan $\left.430^{\circ} \mathrm{C}\right)$ dan konsentrasi asap cair kayu bintangur $(0,0,5,1,0,1,5$ dan $2,0 \%$, v/v). Hasil penelitian menunjukkan bahwa suhu pirolisis produksi asap cair dan konsentrasi asap cair berpengaruh sangat nyata terhadap daya hambat pertumbuhan jamur, S. commune. Kemampuannya sebesar $100 \%$ pada konsentrasi $2 \%$ masing-masing pada suhu pirolisis asap cair 370,400 , dan $430^{\circ} \mathrm{C}$.
\end{abstract}

Kata kunci: asap cair, daya hambat, efikasi, Schizophyllum commune

\begin{abstract}
Study aims to evaluate antifungal properties of wood vinegar from bintangur against S. commune fungus. PDA medium for the efficacy of the wood vinegar of bintangur wood on the growth of S. commune fungus. Three kinds of wood vinegar were used three temperatures i.e. 370,400 and $430{ }^{\circ} \mathrm{C}$. Efficacy of wood vinegar from bintangur wood for antifungal is a factorial 3 by 4 in a completely randomized design; the first factor was pyrolysis temperature of wood vinegar from bintangur $(370,400$, and $430{ }^{\circ} \mathrm{C}$ ) and the second factor was treatment of concentration of wood vinegar from bintangur wood $(0,0.5,1.0,1.5$ and $2.0 \%, \mathrm{v} / \mathrm{v})$. The results showed that pyrolysis temperature effect of wood vinegar from bintangur and concentration of wood vinegar were significantly different for inhibition of fungal growth with temperature pyrolysis of concentration of wood vinegar of $2.0 \%$ at $430{ }^{\circ} \mathrm{C}$ with average value of $100 \%$.
\end{abstract}

Keywords: bintangur wood, efficacy, inhibition of fungal growth, S. commune, 


\section{PENDAHULUAN}

Organisme perusak tanaman (OPT) seperti jamur, rayap, dan serangga merusak tanaman mulai dari benih sampai panen bahkan setelah panen (pasca panen). Pengendalian OPT pada tanaman di lapangan maupun saat pascapanen menggunakan bahan kimia yang mempunyai dampak negatif terhadap lingkungan. Penggunaan bahan alami dalam mengendalikan OPT pada hasil panen bahkan bahan setelah dipanen merupakan cara untuk mengatasi beberapa permasalahan penggunaan bahan kimia. Asap cair merupakan salah satu bahan yang berasal dari alam yang mampu berfungsi sebagai bahan untuk mengendalikan organisme perusak seperti jamur (Theapparat et al. 2015, p. 524), serangga (Prabowo et al., 2016, p. 26) dan rayap (Indrayani dkk., 2012, p. 55).

Asap cair merupakan produk yang dihasilkan melalui proses pembakaran kayu yang mengandung selulosa, hemiselulosa dan lignin. Pembakaran kayu atau biomasa tersebut dilakukan pada suhu tinggi tanpa udara. Akhir-akhir ini para peneliti telah melakukan penelitian penggunaan asap cair dalam rangka mengatasi serangan organisme seperti jamur, bakteri, serangga dan rayap. Upaya dalam rangka mengatasi munculnya dampak tersebut dengan cara pengendalian organisme perusak tersebut dengan menggunakan bahan alami yaitu pemanfaatan asap cair. Kandungan penyusun kayu sebagai bahan baku dalam pembuatan asap cair mempunyai komponen selulosa, hemiselulosa, dan lignin (Stefanidis et al., 2014, p. 17). Bahan baku yang digunakan untuk produksi asap cair adalah bahan yang mudah didapat dan berlimbah. Salah satu limbah kayu bintangur dapat digunakan untuk produksi asap cair.

Beberapa peneliti telah melakukan penelitian penggunaan asap cair sebagai bahan antijamur (Lourencon et al., 2016, p. 6; Theapparat et al., 2015, p. 524) dan antirayap (Rosalina et al. 2016, p. 438). Rosalina et al. (2016, p. 438) menemukan bahwa asap cair yang diperoleh dari kayu bintaro (Cerbera odollam GAERTN) berfungsi sebagai bahan biopestisida terhadap rayap Coptotermes curvignathus HOLMGREN). Asap cair yang diperoleh dari kayu bengkirai mampu menghambat pertumbuhan jamur Phytophtora citrophthora secara in vitro (Oramahi et al. 2018, p. 164). Chuaboon et al. (2016, p. 77) menyatakan bahwa asap cair diperoleh dari bambu mampu menghambat pertumbuhan jamur Cercospora lunata, Bipolaris oryzae, Fusarium semitectum, and Alternaria padwickii secara in vitro. Asap cair yang 
diperoleh dari cangkang kelapa sawit mempunyai komponen utama yaitu fenol dan turunan fenol, dan bersifat sebagai antijamur (Mahmud et al. 2016, p. 1433 ).

Kemampuan asap cair dalam menghambat pertumbuhan jamur dipengaruhi oleh berbagai faktor diantaranya adalah komponen kimia penyusun asap cair. Komponen kimiawi penyusuan asap cair dipengaruhi oleh komponen kimiawi penyusun kayu seperti kandungan selulosa, hemiselulosa dan lignin serta suhu pirolisis dalam produksi asap cair. Suhu pirolisis pembuatan asap cair sebagai faktor penting yang menyebabkan terjadinya perubahan komponen kimiawi penyusun asap cair terutama komponen fenol dan turunannya serta asam organik.

Penggunaan bahan alami sebagai bahan dalam pengendalian kayu menggunakan asap cair dapat dijadikan alternatif, mengingat akhir-akhir ini ketersedian kayu makin terbatas terutama kayu kelas awet I dan kelas awet II, masyarakat beralih mengunakan kayu kelas awet II dan kelas awet IV yang mempunyai tingkat keawetan rendah sehingga mudah terserang jamur. Biopestisida alami yang berasal dari asap cair bisa dijadikan laternatif untuk mengawet kayu pada masa yang akan datang.

Penelitian ini bertujuan untuk mengevaluasi potensi asap cair dari kayu bintangur (Callophyllum soulatri Burm.F.) sebagai biopestisida untuk pengendalian jamur, Schizophyllum commune. S. commune merupakan salah satu jamur penting penyebab menurunnya kualitas kayu.

\section{METODE}

\section{Waktu dan Tempat Penelitian}

Waktu penelitian dilaksanakan mulai bulan Oktober 2019 sampai dengan bulan Februari 2020. Penelitian dilaksanakan di Laboratorium Wood Workshop, Laboratorium Teknologi Kayu, Fakultas Kehutanan, Universitas Tanjungpura, Pontianak dan Laboratorium Rekayasa Fakultas Teknologi Fakultas Pertanian, Universitas Gadjah Mada, Yogyakarta.

\section{Preparasi Bahan}

Kayu bintangur (Callophyllum soulatri Burm.F.) sebagai bahan baku dalam produksi asap cair diperoleh dari Saw Mill di Pontianak. Preparasi bahan baku kayu bintangur dilaksanakan di Laboratorium Wood Workshop, Fakultas Kehutanan, Univeritas Tanjungpura, Pontianak. 


\section{Pirolisis Asap Cair}

Produksi asap cair kayu bintangur dengan menggunakan alat pirolisis (Darmadji, 2019, p. 173). Kayu bintangur terlebih dahulu dikering anginkan dengan cara dihamparkan pada tempat terbuka. Kayu dihaluskan menjadi serbuk dengan alat disk mill. Pembuatan asap cair dilakukan di Laboratorium Rekayasa Fakultas Teknologi Pertanian, UGM, Yogyakarta. Tahapan produksi asap cair sebagai berikut (1) serbuk kayu bintangur diletakan dalam reaktor selanjutnya dapur pemanas dinyalakan menggunakan aliran listrik, (2) suhu pirolisis distel pada suhu pembuatan asap cair yaitu 370, 400, dan $430{ }^{\circ} \mathrm{C}$ dan lama pirolisis antara 90-150 menit, (3) asap yang keluar melalui reaktor dialirkan ke dalam kolom pendingin menggunakan pipa penyalur, dan (4) ke dalam kolom pendingin ini disalurkan air dengan pompa. Embunan yang diperoleh berupa asap cair ditampung mengunakan Erlenmeyer 1 1. Asap cair dipindahkan ke dalam botol dan dibiarkan beberapa hari agar tar yang masih ada bisa mengendap. Asap cair bagian atas dalam botol yang digunakan untuk perlakuan.

Koleksi Isolat dan Efikasi Asap Asap Cair Kayu Bintangur terhadap Jamur, S. commune.

Isolat jamur S. commune diperoleh dari Laboratorium Teknologi Kayu, Fakultas Kehutanan, Universitas Tanjungpura, Pontianak. Isolat jamur S. commune diperbanyak dengan medium PDA. Perbanyakan jamur dilakukan seminggu menjelang perlakuan. Pengujian sifat antijamur asap cair kayu bintangur mengacu metode Mohareb et al. (2013, p. 500) dengan sedikit modifikasi. Suhu pirolisis pembuatan asap cair kayu bintangur yang digunakan adalah 370,400 , dan $430{ }^{\circ} \mathrm{C}$ dan konsentrasi asap cair kayu bintangur yaitu $0,0,5,1,0,1,5$ dan 2,0 \%. Selanjutnya, medium PDA disterilisasi dengan autoclaved pada suhu $121{ }^{\circ} \mathrm{C}$ dan tekanan $103.4 \mathrm{kPa}(15 \mathrm{psi})$ selama 15 menit. Isolat jamur ( $5 \mathrm{~mm}$ ) ditumbuhkan berada tepat ditengah-tengah cawan petri yang berisi media PDA pada konsentrasi dan suhu pirolisis pembuatan asap cair yang berbeda sebagai perlakukan dan sebagai kontrol yaitu cawan petri hanya berisi media PDA. Masing-masing perlakuan dilakukan pengulangan sebanyak 3 kali. Cawan petri (perlakuan dan kontrol) yang sudah diinokulasi jamur diinkubasi pada suhu ruang. Koloni jamur dihitung diamaternya setelah ada koloni yang tumbuh menutupi semua 
cawan petri selama 7 hari. Daya hambat pertumbuhan jamur, S. commune ditentukan dengan cara sebagai berikut:

$$
\mathrm{DHP}=[(\mathrm{K}-\mathrm{P}) / \mathrm{K}] \times 100(\%)
$$

Keterangan DHP = daya hambat pertumbuhan jamur, S. commune dalam \%, K = control yaitu pertumbuhan jamur, $S$. commune atau diameter koloni jamur $(\mathrm{mm})$ dan $\mathrm{P}=$ pertumbuhan jamur, S. commune pada perlakuan asap cair kayu bintangur (mm).

\section{Analisis Data}

Rancangan yang digunakan untuk mengevaluasi pengaruh suhu pirolisis pembuatan asap cair dan konsentrasi asap cair kayu bintangur terhadap daya hambat pertumbuhan jamur, S. commune adalah rancangan acak lengkap dengan pola faktorial. Faktor pertama yaitu suhu pirolisis pembuatan asap cair kayu bintangur terdiri atas 370,400 , dan $430{ }^{\circ} \mathrm{C}$. Faktor kedua yaitu konsentrasi asap cair kayu bintangur terdiri atas $0,0,5,1,0,1,5$ dan 2,0 \% . Data persentase daya hambat asap cair terhadap jamur, $S$. commune dilakukan analisis menggunakan analisis sidik ragam (ANOVA). Pengaruh antarperlakuan dilakukan uji BNJ pada taraf nyata 5\%. Software SAS digunakan untuk analisis data.

\section{HASIL DAN PEMBAHASAN}

Pertumbuhan koloni $S$. commune pada konsentrasi $0-2,0 \%$ pada suhu pirolisis pembuatan asap cair $\left(370,400\right.$, dan $\left.430{ }^{\circ} \mathrm{C}\right)$, disajikan pada Gambar 1-3.
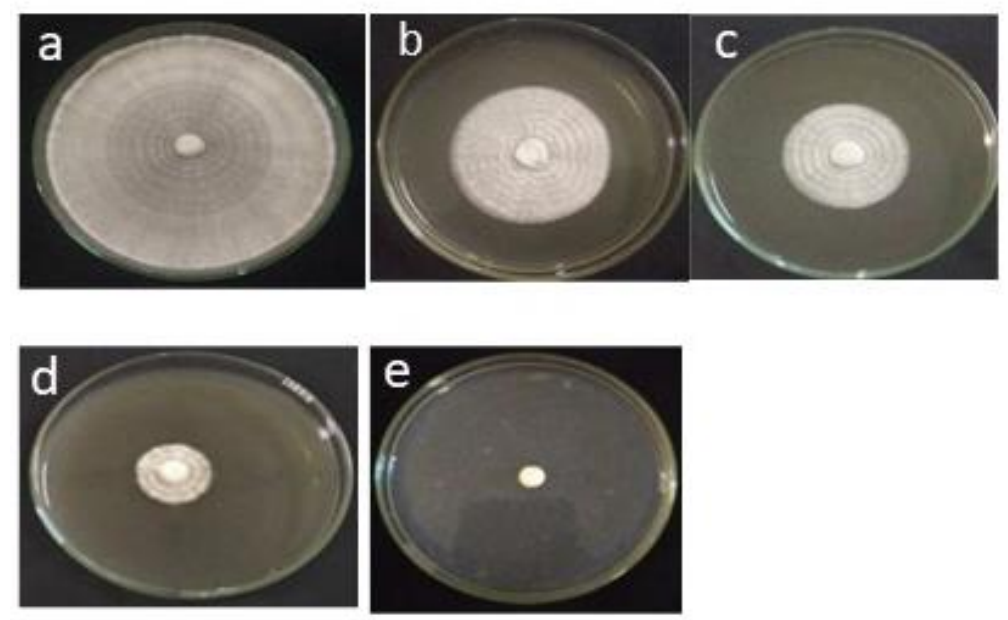

Gambar 1. Pertumbuhan Koloni Jamur S. commune (suhu pirolisis $370{ }^{\circ} \mathrm{C}$ ) pada kontrol $0 \%$ konsentrasi asap cair $0,5 \%$ (b), $1 \%$ (c), $1,5 \%$ (d) dan $2,0 \%$ (e) 

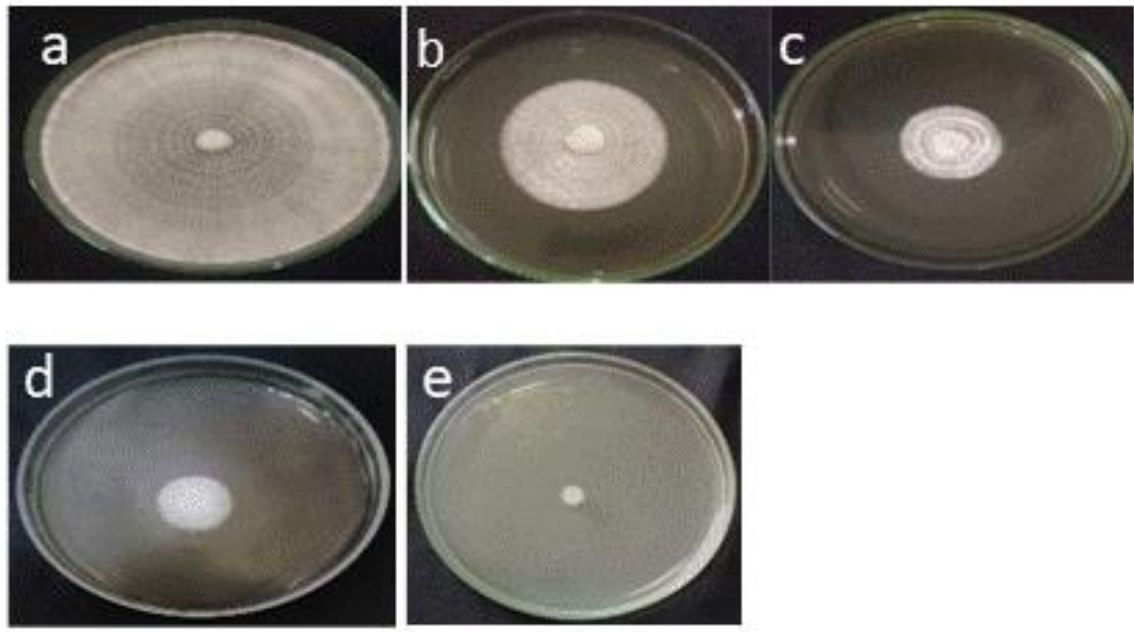

Gambar 2. Pertumbuhan Koloni Jamur S. commune (suhu pirolisis $400{ }^{\circ} \mathrm{C}$ ) pada kontrol $0 \%$ (a), konsentrasi asap cair $0,5 \%$ (b), $1 \%$ (c), $1,5 \%$ (d) dan $2,0 \%$ (e)
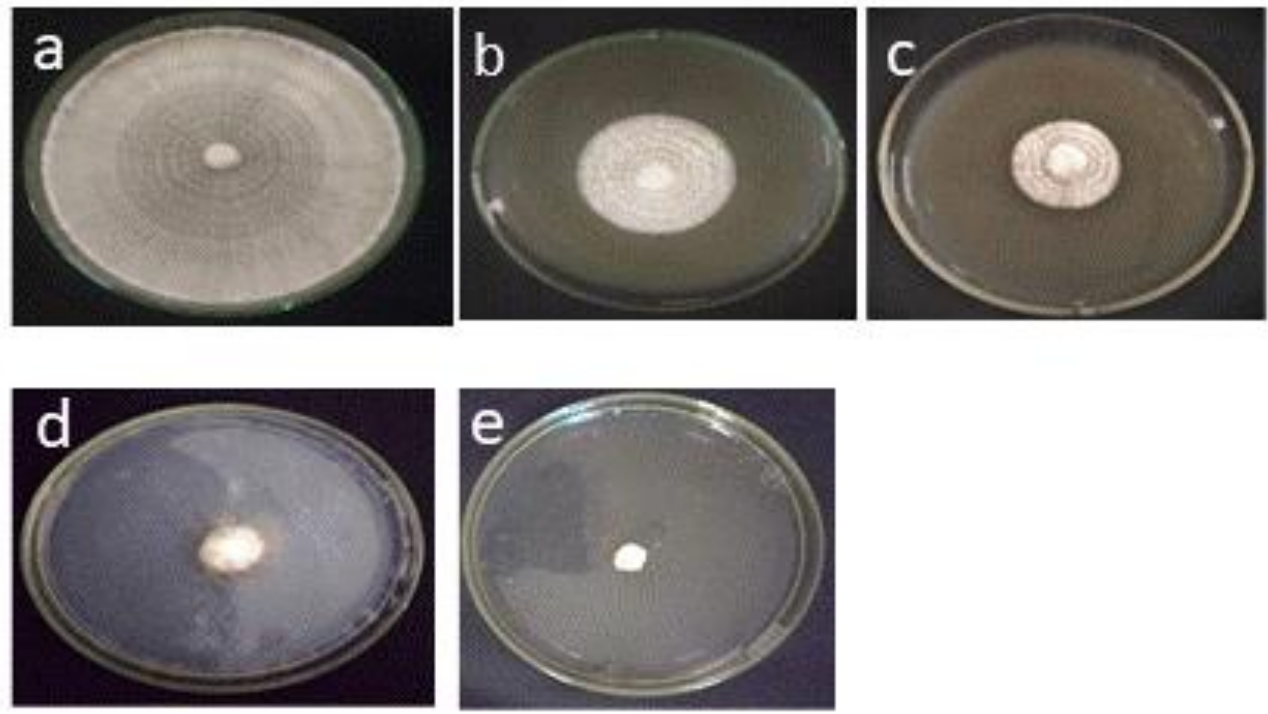

Gambar 3. Pertumbuhan Koloni Jamur S. commune (suhu pirolisis $430{ }^{\circ} \mathrm{C}$ ) pada kontrol $0 \%$ (a), konsentrasi asap cair 0,5\% (b), 1\% (c), 1,5\% (d) dan 2,0\% (e)

Gambar 1-3 menunjukan bahwa asap cair kayu bintangur pada suhu pirolisis pembuatan asap cair $\left(370,400\right.$ dan $\left.430{ }^{\circ} \mathrm{C}\right)$ dan konsentrasi asap cair 0,5-2,0 \%, bahwa adanya tren pertumbuhan jamur makin terhambat dengan naiknya konsentrasi asap cair. Konsentrasi asap cair sebesar $2 \%$ pada suhu pirolisis pembuatan asap cair $(370,400$ dan $430{ }^{\circ} \mathrm{C}$ ), koloni jamur S. commune tidak tumbuh sampai hari ketujuh (akhir 
pengamatan), hal ini membutikan bahwa asap cair mempunyai kemampuan sebagai bahan antijamur terhadap jamur S. commune.

Daya hambat asap cair kayu bintangur dalam menghambat pertumbuhan jamur, $S$. commune pada konsentrasi $(0,0,5,1,0,1,5$ dan 2,0 \%) dan suhu pirolisis pembuatan asap cair kayu bintangur $\left(370,400\right.$, dan $\left.430{ }^{\circ} \mathrm{C}\right)$, disajikan pada Tabel 1.

Tabel 1. Daya Hambat Asap Cair dari Kayu Bintangur Terhadap Jamur, Schizophyllum commune

\begin{tabular}{|c|c|c|}
\hline \multicolumn{2}{|c|}{ Perlakuan } & \multirow[b]{2}{*}{$\begin{array}{l}\text { Daya Hambat } \\
\text { pertumbuhan jamur } \\
\text { Schizophyllum comn }\end{array}$} \\
\hline $\begin{array}{l}\text { Suhu pirolisis } \\
\text { asap cair kayu } \\
\text { bintangur }\left({ }^{\circ} \mathrm{C}\right) \\
\end{array}$ & $\begin{array}{c}\text { Konsentrasi asap } \\
\text { cair kayu bintangur } \\
(\%)\end{array}$ & \\
\hline Kontrol & 0 & $0 \pm 0 \mathrm{a}$ \\
\hline \multirow[t]{4}{*}{370} & 0,5 & $57,10 \pm 6,04 b$ \\
\hline & 1,0 & $83,03 \pm 0,71 \mathrm{~d}$ \\
\hline & 1,5 & $86,84 \pm 1,59 d$ \\
\hline & 2,0 & $100 \pm 0 \mathrm{f}$ \\
\hline \multirow[t]{4}{*}{400} & 0,5 & $66,70 \pm 7,23 \mathrm{c}$ \\
\hline & 1,0 & $83,03 \pm 0,71 \mathrm{~d}$ \\
\hline & 1,5 & $92,43 \pm 1,31 \mathrm{e}$ \\
\hline & 2,0 & $100 \pm 0 \mathrm{f}$ \\
\hline \multirow{4}{*}{430} & 0,5 & $71,00 \pm 6,96 \mathrm{c}$ \\
\hline & 1,0 & $83,03 \pm 0,71 \mathrm{~d}$ \\
\hline & 1,5 & $92,35 \pm 1,31 \mathrm{e}$ \\
\hline & 2,0 & $100 \pm 0 \mathrm{f}$ \\
\hline
\end{tabular}

Rerata yang diikuti oleh huruf yang sama berarti tidak berbeda nyata pada level $P<0.05$ berdasarkan Uji BNJ

Tabel 1 menunjukkan bahwa makin tinggi konsentrasi asap cair kayu bintangur makin tinggi daya hambat pertumbuhan jamur, Schizophyllum commune. Suhu pirolisis pembuatan asap cair dan konsentrasi asap cair berpengaruh sangat nyata terhadap pertumbuhan jamur, S. commune. Komponen kimia asap cair didominasi oleh kelompok asam organik dan fenol. Kedua komponen ini berfungsi sebagai bahan antijamur. Mekanisme aktivitas senywa fenol sebagai bahan antijamur yaitu adanya 
reaksi membran sel yang dapat menagkibatkan proses permeabilitas membran sel terganggu atau adanya inaktivasi enzim-enzim esensial dan dapat juga terjadi adanya kombinasi dari keduanya (Davitson \& Branen, 1981 dalam Oramahi et al. 2018, p. 164). Setiawati et al. (2019, p. 5) menyatakan bahwa asap cair yang diperoleh dari kayu durian pada suhu $350{ }^{\circ} \mathrm{C}$ mempunyai komponen aktif seperti 4 metil fenol, 2 metoksi fenol, 2 metoksi 4 metil fenol dan 2 etil 2 metoksi fenol berturut turut sebesar 9,19, $37,07,25,25,16,02 \%$ dan pada suhu $450{ }^{\circ} \mathrm{C}$ berturut turut sebesar $11,84,38,31,23,28$ dan $23,28 \%$.

Hou et al. (2018, p. 40941) menyatakan bahwa komponen penyusun asap cair dari Eucommia ulmoides terdiri atas fenol, keton, aldehid, alkohol, asam organik dan benzen. Asap cair yang diperoleh mempunyai aktivitas sebagai bahan antijamur terhadap jamur penicillium, Aspergillus, dan Rhizopus. Priyamto et al. (2013, p. 28) melaporkan bahwa asap cair yang diperoleh dari kayu leban mempunyai daya aktivitas sebagai bahan antijamur terhadap jamur A. niger. Konsentrasi asap cair 5\% mampu menghambat pertumbuhan jamur sebesar $100 \%$. Sifat antijamur asap cair disebabkan oleh adanya sinergisnya antara kandungan asam organik dan kandungan fenolik penyusun asap cair (Barbero-López et al. 2019, p. 609)

Asap cair yang diperoleh dari cangkang kelapa sawit mempunyai komponen utama yaitu fenol dan turunan fenol, dan bersifat sebagai antijamur (Mahmud et al. 2016, p. 1433). Theapparat et al. (2015, p. 517) melaporkan bahwa asap cair dari Eucalyptus camaldulensis, Leucaena leucocephala, Azadirachta indica, Hevea brasiliensis dan Dendrocalamus asper mempunyai sifat sebagai bahan antijamur dalam menghambat pertumbuhan jamur Trametes versicolor dan Rigidoporopsis amylospora dan Gleophyllum trabeum. Sharip et al. (2016, p. 3) melaporkan bahwa asap cair yang diperoleh dari hasil pirolisis mesocarp buah kelapa sawit mempunyai 62 komponen yang terdiri atas kelompok fenol, keton, furan, piran, keton, eseter, alkohol, aldehid, dan kelompok asam. Asap cair yang dihasilkan mempunyai aktivitas terhadap Ganoderma boninense, Aspergillus fumigatus dan Trichoderma asperellum.

\section{KESIMPULAN DAN SARAN}

Asap cair kayu bintangur yang diproduksi pada suhu 370 , 400, dan $430{ }^{\circ} \mathrm{C}$ mempunyai kemampuan sebagai bahan antijamur dalam menghambat pertumbuhan 
jamur, Schizophyllum commune. Suhu pirolisis produksi asap cair kayu bintangur dan konsentrasinya mempunyai pengaruh nyata dalam menghambat pertumbuhan jamur, $S$. commune. Kemampuan asap cair dalam menghambat pertumbuhan jamur, S. commune tertinggi diperoleh pada konsentrasi asap cair sebesar $2 \%$ pada suhu 370, 400, dan 430 ${ }^{\circ} \mathrm{C}$. Kemampuan asap cair dalam menghambat pertumbuhan jamur, S. commune menunjukan adanya potensi asap cair sebagai bahan biopestisida.

Penelitian ini dilakukan secara in vitro dan untuk mengevaluasi lebih lanjut kemampuan asap cair sebagai biopestisida perlu dilakukan pengujian asap cair terhadap organisme penyebab penyakit tanaman maupun organisme perusak kayu secara in vivo. Komponen kimia penyusun asap cair kayu bintangur perlu diidentifikasi dan dianalisis untuk mengevaluasi komponen aktif yang berperan sebagai bahan biopestisida.

\section{UCAPAN TERIMA KASIH}

Penelitian ini merupakan bagian dari Skema Penelitian Tesis Magister dengan judul Optimasi Produksi Asap Cair Kayu Bintangur dan Medang dengan Response Surface Methodology (RSM) dan Potensinya Sebagai Antijamur dan Antirayap yang dibiayai oleh Kementerian Riset dan Teknologi/Badan Riset dan Inovasi Nasional anggaran tahun 2020 dengan nomor kontrak SP DIPA-042.06.1.401516/2020, dan melibatkan dua orang mahasiswa S-2 Program Magister Kehutanan, Fakultas Kehutanan, Universitas Tanjungpura a.n. Juanita dan Rizka Dia Permana. Sehubugan dengan itu, penulis ucapkan terima kasih atas dukungan dana untuk penelitian ini.

\section{DAFTAR PUSTAKA}

Barbero-López, A., Chibily, S., Tomppo, L., Salami, A., Ancin-Murguzur, F. J., Venäläinen, M., Lappalainen, R. \& Haapala, A. (2019). Pyrolysis Distillates from Tree Bark and Fibre Hemp Inhibit The Growth of Wood-decaying Fungi. Industrial Crops and Products, 129, 604-610

Chuaboon, W., Ponghirantanachoke, N., \& Athinuwat, D. (2016). Application of Wood Vinegar for Fungal Disease Controls in Paddy Rice. Applied Environmental Research, 38(3), 77-85.

Darmadji, P., 2002. Optimasi Proses Pembuatan Tepung Asap, Agritech, 4: 172-177 
Hou, X., Qiu, L., Luo, S., Kang, K., Zhu, M., \& Yao, Y. (2018). Chemical Constituents and Antimicrobial Activity of Wood Vinegars at Different Pyrolysis Temperature Ranges Obtained from Eucommia Ulmoides Olivers Branches. RSC advances, 8(71), 40941-40949.

Indrayani, Y., Oramahi, H. A., Nurhaida. (2012) Evaluasi Asap Cair Sebagai BioTermitisida untuk Pengendalian Rayap Tanah Coptotermes sp. Jurnal Tengkawang 1: 87-96.

Lourençon, T. V., Mattos, B. D., Cademartori, P. H., \& Magalhães, W. L. (2016). Biooil from a Fast Pyrolysis Pilot Plant as Antifungal and Hydrophobic Agent for Wood Preservation. Journal of analytical and applied pyrolysis, 122, 1-6.

Mahmud, K. N., Yahayu, M., Sarip, S. H. M., Rizan, N. H., Min, C. B., Mustafa, N. F., Ngadiran, S., Ujang, S \& Zakaria, Z. A. (2016). Evaluation on Efficiency of Pyroligneous Acid from Palm Kernel Shell as Antifungal and Solid Pineapple Biomass as Antibacterial and Plant Growth Promoter. Sains Malaysiana, 45(10), 1423-1434.

Mohareb, A. S., Badawy, M. E., \& Abdelgaleil, S. A. (2013). Antifungal Activity of Essential Oils Isolated from Egyptian Plants Against Wood Decay Fungi. Journal of wood science, 59 (6), 499-505.

Oramahi, H. A., Wardoyo, E. R. P., \& Kustiati, K. (2018). Efikasi Asap Cair dari Kayu Bengkirai terhadap Phytophthora citrophthora. Jurnal Perlindungan Tanaman Indonesia, 22(2), 160-166.

Prabowo, H., Martono, E., \& Witjaksono, W. (2016). Activity of Liquid Smoke of Tobacco Stem Waste as An Insecticide on Spodoptera Litura Fabricius Larvae. Jurnal Perlindungan Tanaman Indonesia, 20(1), 22-27.

Priyamto S, Oramahi HA, Wahdina, Diba F. (2013). Aplikasi Asap Cair dari Kayu Leban (Vitex pubescens Vahl) untuk Pengendalian Jamur pada Benih Tusam (Pinus merkusii Jungh et de Vriese) Secara In Vitro. Jurnal Hutan Lestari 1(1): 23-29.

Rosalina, T. T., Riani, E., \& Sugiarti, S. (2016). An environmental Friendly Pesticide from Bintaro (Cerbera odollam gaertn) Liquid Smoke for Pine Wood Preservation Against a Subterranean Termite Captotermes curvignathus Holmgren Attack. Rasayan J Chem, 9 (3), 438-443. 
Setiawati, E., Annisa, W., Soedarmanto, H., \& Iskandar, T. (2019). Characterization of Neutralized Wood Vinegar Derived from Durian Wood (Durio Zibethinus) and Its Prospect As Pesticide In Acidic Soil. In IOP Conference Series: Earth and Environmental Science (Vol. 393, No. 1, p. 012051). IOP Publishing.

Sharip, N.S., Ariffin, H., Hassan, M.A., Nishida, H. \& Shirai, Y. (2016). Characterization and Application of Bioactive Compounds in Oil Palm Mesocarp Fiber Superheated Steam Condensate as an Antifungal Agent. RSC Advances, 6 (88):84672-84683.

Stefanidis, S. D., Kalogiannis, K. G., Iliopoulou, E. F., Michailof, C. M., Pilavachi, P. A., \& Lappas, A. A. (2014). A Study of Lignocellulosic Biomass Pyrolysis Via The Pyrolysis of Cellulose, Hemicellulose and Lignin. Journal of Analytical and Applied Pyrolysis 105, 143-150.

Theapparat, Y., A. Chandumpai, W. Leelasuphakul, N. Laemsak. (2015). Pyroligneous Acids from Carbonisation of Wood and Bamboo: Their Components and Antifungal Activity. Journal of Tropical Forest Science 27: 517-526. 